\title{
Presynaptic inhibition of soleus Ia afferent terminals in Parkinson's disease
}

\author{
R C Roberts, N J Part, Ruth Farquhar, Pamela Butchart
}

\begin{abstract}
The possible role of changes in presynaptic inhibition of muscle spindle primary afferent terminals in Parkinson's disease was investigated. The pathway from tibialis anterior Ia afferents to soleus Ia terminals was assessed in 20 patients with Parkinson's disease and in 17 age matched controls, both at rest and during maintenance of tonic plantar flexing torques about the ankle. At all torques less presynaptic inhibition was present in the patients with Parkinson's disease than in the controls. The difference was significant at rest $(p<0.03)$ and at $2 \mathrm{Nm}$ $(p<0.05)$ but not at $5 \mathrm{Nm}$ and $7 \mathrm{Nm}$ torque. The amount of presynaptic inhibition did not change with torque in either group. The observed alteration in presynaptic inhibition in Parkinson's disease is likely to make only a small contribution to the rigidity and impaired movement control.
\end{abstract}

(F Neurol Neurosurg Psychiatry 1994;57:1488-1491)

The mechanisms underlying rigidity in Parkinson's disease remain uncertain. The rigidity is not due to a pronounced increase in motoneuron excitability ${ }^{12}$ or to a change in fusimotor control causing an increase in spindle primary afferent responses to stretch. ${ }^{3}$ Nevertheless, the alleviation of rigidity after section of the posterior spinal roots confirmed that it is dependent on the primary afferent input evoked by stretch. ${ }^{4}$ Changes in transmission in various excitatory and inhibitory reflex pathways from both cutaneous ${ }^{5}$ and muscle primary afferents have been described in Parkinson's disease. There is now consensus that long latency stretch reflexes are enhanced, ${ }^{67}$ suggesting that increased transmission in the transcortical and other pathways mediating them might play a part in rigidity. Decreased transmission in various inhibitory spinal reflex pathways might also contribute but the evidence is more conflicting. There is a pronounced reduction in Ib inhibition in parkinsonian patients. ${ }^{8}$ Reciprocal inhibition was recently reported to be decreased in the upper limbs of patients with Parkinson's disease, ${ }^{9}$ but previous evidence suggested increased reciprocal inhibition. ${ }^{1011}$ Recurrent inhibition on the other hand is unchanged. ${ }^{19}$ Presynaptic inhibition of Ia terminals was reported to be decreased when elicited by electrical stimulation of an antagonist nerve in the upper $\operatorname{limb}^{9}$ but to be normal when elicited by continuous vibration of the homonymous muscle in the lower limb. ${ }^{112}$ In this study we have used a more selective technique to examine whether or not decreased presynaptic inhibition of Ia terminals might contribute to the rigidity and impaired control of movement in Parkinson's disease and we have assessed the descending control of transmission in the pathway mediating the inhibition.

Some of the data have been previously published in abstract form. ${ }^{13}$

\section{Methods}

The methods used in this investigation have been described fully in a previous paper. ${ }^{14} \mathrm{~A}$ quantitative assessment of the transmission through the pathway mediating presynaptic inhibition of the soleus Ia afferent terminals from anterior tibial Ia afferent neurons was made by measuring the reduction in the size of the soleus $\mathrm{H}$ reflex produced by a conditioning vibration pulse applied to the anterior tibialis muscle. The conditioning test interval was $60 \mathrm{~ms}$ and the vibration pulse consisted of 3 pulses of 0.5 to $1 \mathrm{~mm}$ amplitude at $100 \mathrm{~Hz}$. The inhibition seen at this conditioning interval is mainly mediated by presynaptic inhibition of the soleus Ia terminals. ${ }^{15}$ The mean value of 10 conditioned test reflexes was expressed as a percentage of the mean value of 10 unconditioned reflexes $(\mathrm{C} / \mathrm{T} \%)$. Measurements of presynaptic inhibition were made over a range of tonic plantarflexing torques from 0 to $7 \mathrm{Nm}$ at an ankle angle of $90^{\circ}$; $7 \mathrm{Nm}$ was the greatest torque that the patients with Parkinson's disease could sustain over the approximate two minute period required to make a $\mathrm{C} / \mathrm{T}$ measurement.

Twenty patients with idiopathic Parkinson's disease were recruited from those attending the neurology clinic at Dundee Royal Infirmary. They were aged between 55 and 79 (mean 67). Patients with significant lower limb tremor or dyskinesia were excluded. All were taking and had been responsive to dopaminergic medication and they were continued on their usual medication when studied. The duration of symptoms varied from one to 15 (mean $8 \cdot 1$ ) years and the duration of dopaminergic treatment from three to 156 (mean 48) months. The Webster 


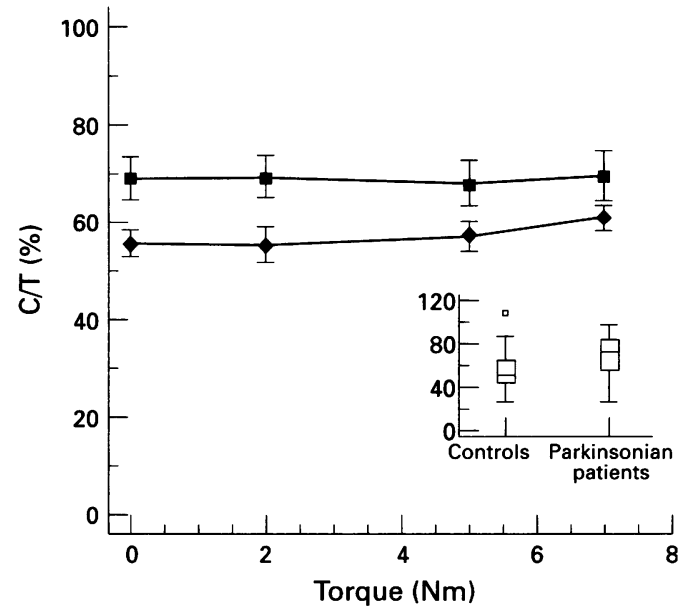

Figure 1 Graphs of mean value of the ratio of conditioned to test $H$ reflex amplitude for all patients in Parkinson's disease group (squares) and age matched control group (diamonds) plotted against torque generated at the ankle. Bars indicate SEM. The difference between the two groups was significant at $0 \mathrm{Nm}(p=0.03)$ and 2 $N m(p<0.05, t$ test). Inset: box and whisker plots (the midline represents the median value, the boxes the inner quartiles, the lines the outer quartiles and the square an outlier) of the ratio of conditioned to test $H$ reflex amplitude for the data at $0 \mathrm{Nm}$ torque.

rating at the time of study varied from 1 to 24 (mean 9.6). The leg on the more severely affected side was studied and the tone in it was assessed clinically on a scale from 0 to 3 ( 0 normal tone; 1 mild rigidity; 2 moderate rigidity; 3 severe rigidity).
Seventeen normal control subjects were recruited from a fitness class. They had no neurological or other medical symptoms. Data from this control group have been presented in a previous paper. ${ }^{14}$ They were aged between 59 and 74 (mean 66.6). Age matching between the patients with Parkinson's disease and controls is of importance because of the effects of age on the presynaptic inhibitory pathway assessed ${ }^{14}{ }^{16}$; there was no significant difference between the means of the control sample and the patient sample.

Local ethics committee approval was given.

\section{Results}

Figure 1 (inset) shows the results obtained on presynaptic inhibition of soleus Ia terminals at zero torque ("leg relaxed"). The amount of inhibition evoked by the Ia afferent volleys from tibialis anterior varied considerably between different persons, with pronounced overlap between the patients with Parkinson's disease and controls. There was a significant difference between the two groups $(p=0.03$, $t$ test), however, with less presynaptic inhibition in patients with Parkinson's disease (median $\mathrm{C} / \mathrm{T} 72 \%$ ) than in the controls (median $\mathrm{C} / \mathrm{T} 51 \%$ ). The groups were also significantly different when age was taken into account as a covariant ( $p=0.03$, analysis of variance (ANOVA)).

The effect of tonic plantarflexing torque on transmission in the pathway mediating the

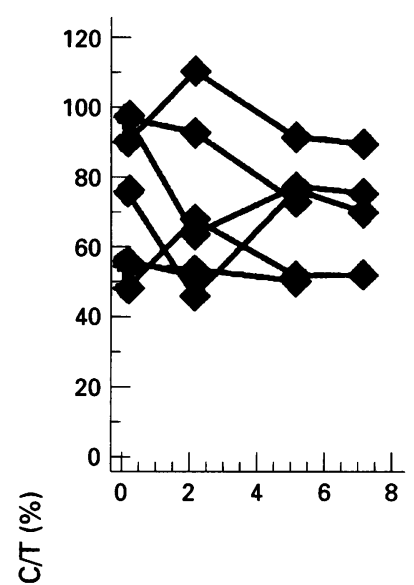

Parkinsonian patients
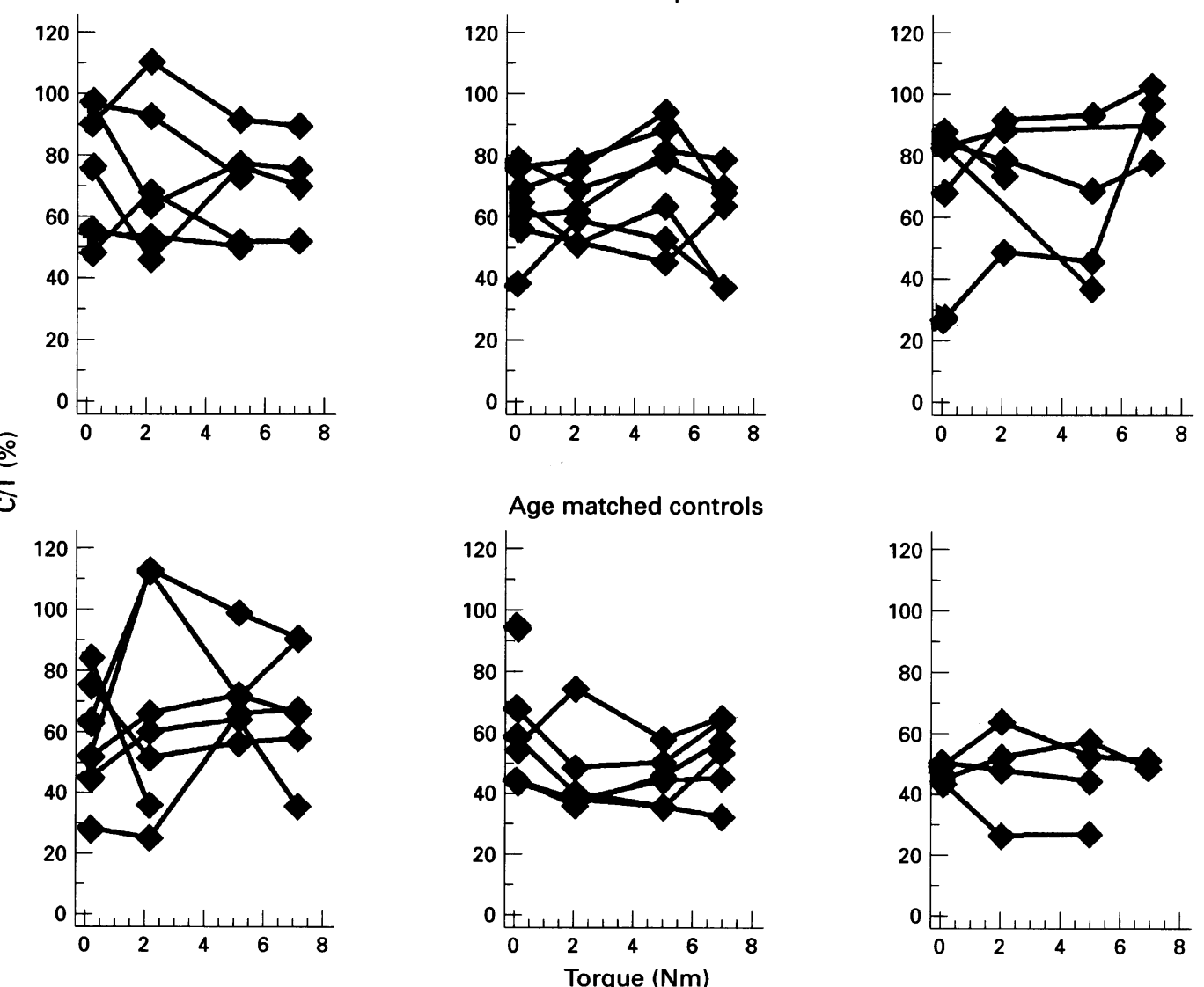

Figure 2 Plots of the ratio of conditioned to test $H$ reflex amplitude against torque generated at the ankle for patients with Parkinson's disease and age-matched controls. Data from the first subjects investigated are shown in the left hand graphs and from the last in the right hand graphs. 
presynaptic inhibition of soleus Ia terminals was investigated. Figure 2 shows the $C / T$ ratios obtained in each patient and control over a range of torques between 0 and $7 \mathrm{Nm}$. There was no consistent change in the amount of inhibition as torque increased in those of either group. Only one of the patients with Parkinson's disease showed the progressive decrease in presynaptic inhibition with increasing torque seen in younger normal subjects. ${ }^{14}$ Figure 1 shows the mean $\mathrm{C} / \mathrm{T}$ ratios at different torques for the patients with Parkinson's disease and the controls. There was no significant effect of increasing torque on presynaptic inhibition in either group. At all torque levels used there was less inhibition in those with Parkinson's disease than in the controls. As at zero torque, the difference at 2 $\mathrm{Nm}$ was significant ( $\mathrm{p}<0.05, t$ test) but the differences at 5 and $7 \mathrm{Nm}$ were not.

No significant relation was found (regression analysis, ANOVA) between the amount of presynaptic inhibition as reflected by the $\mathrm{C} / \mathrm{T}$ ratio and various clinical variables (rigidity in limb studied, Webster rating, duration of disease, duration of dopaminergic treatment). The distribution of the sizes of the test reflexes used (measured relative to the maximum $M$ response) was similar in the patients with Parkinson's disease and controls. Size of the test reflex did not contribute significantly to the variance of the amount of presynaptic inhibition in either group individually or both groups combined.

\section{Discussion}

We have shown that the inhibition of a soleus test reflex by a brief conditioning pulse of vibration to tibialis anterior at a conditioning test interval of $60 \mathrm{~ms}$ is reduced in patients with Parkinson's disease compared with age matched controls. The evidence for the conclusion that this inhibition provides a measure of presynaptic inhibition of soleus Ia terminals has been presented in a previous paper. ${ }^{14}$ An advantage of the technique is its simplicity, which is important when studying older patient groups. A potential problem is that the amount of presynaptic inhibition measured could vary with the size of the test reflex employed, ${ }^{17}$ particularly with very small or large reflexes (relative to the maximal $M$ response). The test stimulus was adjusted to give $\mathrm{H}$ reflexes on the ascending limb of the recruitment curve that were either about a third of the amplitude of the maximal $M$ response or (if the maximal $\mathrm{H}$ reflex was less than this) were near the top of the recruitment curve. Within the range of test reflex sizes used, the amount of inhibition measured should have been relatively insensitive to reflex size. Confirmation of this was provided by the finding that there was no relation between reflex size and the amount of presynaptic inhibition in either group. The difference in presynaptic inhibition in patients with Parkinson's disease and controls cannot be ascribed to a difference in the reflex sizes employed, as a similar range was used in each group. The difference is also unlikely to be related to a reduced mechanical sensitivity of muscle spindle primary afferents in the patients with Parkinson's disease because they show no alteration of tendon reflexes. ${ }^{18}$

Evidence for reduced presynaptic inhibition of Ia terminals in Parkinson's disease was also found in a study on the upper limb (flexor carpi ulnaris test reflex conditioned by a radial nerve stimulus), ${ }^{9}$ although the controls in this study were not age matched. Reduced presynaptic inhibition in patients with Parkinson's disease compared with age matched controls was not found, however, when soleus $\mathrm{H}$ reflexes were conditioned by continuous vibration of the soleus muscle itself. ${ }^{12}$ There are several possible explanations for the difference between our results and these previous findings on the presynaptic inhibition of soleus Ia terminals. Continuous vibration is a complex conditioning stimulus and may have effects other than presynaptic inhibition, ${ }^{19}$ which might have obscured a decrease in presynaptic inhibition. Alternatively the difference in the responses from heteronymous and from homonymous afferents could be due to Parkinson's disease differentially affecting transmission from these two types of afferent to the Ia terminals. It would have been of interest to assess the presynaptic inhibition of the monosynaptic quadriceps Ia afferents on soleus motoneurons in patients with Parkinson's disease. In young normal subjects we have obtained preliminary evidence of a differential control of transmission in the pathways to these quadriceps Ia terminals and to the soleus Ia terminals. The technique used for assessing presynaptic inhibition of the quadriceps terminals is, however, complex ${ }^{20}$ and could not be easily applied to the older subject groups.

A reduction in presynaptic inhibition of Ia terminals could contribute to the enhancement of tonic vibration reflexes described in Parkinson's disease. ${ }^{2}$ It is also possible that it could contribute to the enhancement of long latency (M2) stretch reflexes seen in Parkinson's disease. ${ }^{67}$ If this were the case, one might expect to see enhanced M2 responses in older subjects and in patients with upper motoneuron lesions, in whom presynaptic inhibition of soleus Ia terminals by tibialis anterior Ia afferents is also reduced. ${ }^{141621}$ In patients with upper motoneuron lesions $\mathrm{M} 2$ is, however, reduced or absent. ${ }^{22}$ This could be simply explained by the interruption of a transcortical pathway by the lesions. An increase in M2 with age has not been described and if it exists it must be much less pronounced than the increase seen in Parkinson's disease. This makes it unlikely that the decrease in presynaptic inhibition in Parkinson's disease contributes significantly to the increase in $\mathrm{M} 2$.

A notable feature of the long latency stretch reflex is that vibration fails to elicit it, both in normal subjects and in patients with Parkinson's disease. ${ }^{23}$ It has been argued that this is evidence for it being mediated by group 
II afferents but alternative explanations are: (a) that vibration of a contracting muscle entrains Ib afferents and evokes homonymous $\mathrm{Ib}$ inhibition and $(b)$ that the high frequency synchronous activation of Ia afferents produces pronounced presynaptic inhibition of homonymous Ia terminals. The reduction of presynaptic inhibition we have found in Parkinson's disease is not, however, associated with enhancement of the M2 response to vibration..$^{23}$ This suggests that the second of the alternative explanations given for the absence of an M2 response to vibration is either incorrect or quantitatively unimportant.

The patients with Parkinson's disease in this study were all taking dopaminergic medication. It is uncertain, therefore, whether the changes in presynaptic inhibition were due to the Parkinson's disease (all patients were symptomatic) or due to the treatment. The second possibility needs considering because levodopa produces profound changes in transmission in spinal reflex pathways in cats with spinal transection ${ }^{24}$ and, furthermore, dopaminergic neurons have been described in the spinal cord. ${ }^{25}$ The types of changes in spinal reflex pathways produced by levodopa in the spinal cat, however, have not been described in patients with Parkinson's disease on therapeutic doses. The change in presynaptic inhibition is most likely to be mediated by a change in the activity of the descending spinal pathways that exert control of transmission to Ia terminals from primary afferents.

The reduction of presynaptic inhibition in Parkinson's disease is likely to make only a small contribution to rigidity or the impaired control of movement. Whereas the reduction in Ib inhibition in Parkinson's disease correlates with the rigidity of the patient ${ }^{8}$ the reduction of presynaptic inhibition and the changes in other reflex pathways ${ }^{6}{ }^{9}$ show no clear relation to the clinical features. Moreover, the difference in presynaptic inhibition between younger and older normal subjects ${ }^{14}$ is much more striking than the difference between patients with Parkinson's disease and their (older, age matched) controls. The younger subjects not only had much greater presynaptic inhibition at zero torque but also showed a progressive decrease in inhibition with increasing torque, such that at high torques it was suppressed. The older subjects and those with Parkinson's disease did not show this presumed supraspinal control of the pathways mediating the presynaptic inhibition. Understanding of the role of these pathways in the control of movement, therefore, is more likely to come from comparison of older and younger normal subjects than from the study of patients with Parkinson's disease.
This work was supported by the Parkinson's Disease Society of the United Kingdom.

1 Delwaide PJ. Are there modifications in spinal cord functions of parkinsonian patients? In: Delwaide PJ, Agnoli $\mathrm{A}$, et al, eds. Clinical neurophysiology in parkinsonism. Amsterdam: Elsevier Science Publishers BV, 1985: Amsterdan.

2 McLellan DL. Dynamic spindle reflexes and the rigidity of Parkinsonism. I Neurol Neurosurg Psychiatry 1973;36: 342-9.

3 Burke D, Hagbarth K-E, Wallin G. Reflex mechanisms in parkinsonian rigidity. Scand $\mathcal{f}$ Rahabil Med 1977;9: 15-23.

4 Foerster O. Zur Analyse und Pathophysiologie der striaten Bewegungsstorungen. Zeitschrift für die gesamte Neurologie und Psychiatrie 1921;73:1-169.

5 Fuhr $P$, Zeffiro $T$, Hallett $M$. Cutaneous reflexes in Parkinson's disease. Muscle Nerve 1992;15:733-9.

6 Rothwell JC, Obeso JA, Traub MM, Marsden CD. The behaviour of the long-latency stretch reflex in patients with Parkinson's disease. I Neurol Neurosurg Psychiatry 1983;46:35-44.

7 Bergui M, Lopiano L, Paglia G, Quattrocolo G, Scarzella L, Masco B. Stretch reflex of quadriceps femoris and its relation to rigidity in Parkinson's disease. Acta Neurol relation to rigidity in
$S$ cand $1992 ; 86: 226-9$.

8 Delwaide PJ, Pepin JL, Maertens de Noordhout A. Shortlatency autogenic inhibition of patients with parkinsonian rigidity. Ann Neurol 1991;30:83-9.

9 Lelli S, Panizza M, Hallett $M$. Spinal cord inhibitory mechanisms in Parkinson's disease. Neurology 1991;41: 553-6.

10 Obeso JA, Quesada P, Artieda J, Martinez-Lage JM Reciprocal inhibition in rigidity and dystonia. In: Delwaide PJ, Agnoli A, et al, eds. Clinical neurophysiology in parkinsonism. Elsevier Science Publishers BV, 1985: in parkin.

11 Bathien N, Rondot P. Reciprocal continuous inhibition in rigidity of Parkinsonism. $\mathcal{F}$ Neurol Neurosurg Psychiatry 1977;40:20-4.

12 Delwaide PJ, Pepin JL, Maertens de Noordhout A. The audiospinal reaction in Parkinsonian patients reflects functional changes in reticular nuclei. Ann Neurol 1993, 33:63-9.

13 Butchart P, Farquhar R, Part NJ, Roberts RC. Reduced presynaptic inhibition of ankle extensor Ia afferents in patients with Parkinson's disease. $\mathcal{F}$ Physiol (Lond) 1990;420:23P

14 Butchart P, Farquhar R, Part NJ, Roberts RC. The effect of age and voluntary contraction on presynaptic inhibition of soleus muscle Ia afferent terminals in man. Exp Physiol 1993;78:235-42.

15 Morin C, Pierrot-Deseilligny E, Hultborn $H$. Evidence for presynaptic inhibition of muscle spindle Ia afferents in man. Neurosci Lett 1984;44:137-42.

16 Delwaide PJ. Human monosynaptic reflexes and presynaptic inhibition. In: Desmedt JE, ed. New developments in electromyography and clinical neurophysiology. Basle: electromyography and

17 Crone C, Hultborn H, Mazieres L, Morin C, Nielsen J, Pierrot-Deseilligny E. Sensitivity of monosynaptic test reflexes to facilitation and inhibition as a function of the test reflex size: a study in man and cat. Exp Brain Res 1990;81:35-45.

18 McLellan DL. Rigidity. In: Clifford Rose F, Capildeo R, et al, eds. Progress in neurology. Kent: Pitman Medical, 1981:88-97.

19 Meunier S, Pierrot-Deseilligny E. Gating of the afferent volley of the monosynaptic stretch reflex during movement in man. F Physiol (Lond) 1989;419:753-63.

20 Hultborn H, Meunier S, Morin C, Pierrot-Deseilligny E. Assessing changes in presynaptic inhibition of Ia fibres in man and the cat. $\mathcal{F}$ Physiol (Lond) 1987;389:729-756.

man and the cat. F Physiol (Lond) 1987;389:729-756.
21 Isles JF, Roberts RC. Presynaptic inhibition of monosynaptic reflexes on the lower limb of subjects with upper naptic reflexes on the lower limb of subjects with upper
motoneuron disease. $\mathcal{F}$ Neurol Neurosurg Psychiatry 1986; motoneuron

22 Marsden CD, Merton PA, Morton HB, Adam A. The effect of lesions of the sensorimotor cortex and the capsular pathways on servo responses from the human long thumb flexor. Brain 1977;100:503-26.

23 Cody FWJ, MacDermott N, Matthews PBC, Richardson HC. Observations on the genesis of the stretch reflex in Parkinson's disease. Brain 1986;109:229-49.

24 Anden N-E, Jukes MGM, Lundberg A, Vyklicky L. The effect of DOPA on the spinal cord 3. Depolarization evoked in the central terminals of ipsilateral Ia afferents by volleys in the flexor reflex afferents. Acta Physiol Scand 1966;68:322-36.

25 Commissiong JW, Neff NH. Current status of dopamine in the mammalian spinal cord. Biochem Pharmacol 1979;28:1569-73. 